\title{
Research of Virtools Virtual Reality Technology to Landscape Designing
}

\author{
Hongjun Chen
}

\author{
Hebei University of Engineering, Architecture College Handan, Hebei, 056038, China
}

\begin{abstract}
The technology of virtual reality is an advanced computer user interface technology, which provides users with a variety of intuitive and natural real-time senses and interactive means in the aspects of vision, touch, taste, etc, thus realizing the most convenient user-computer interaction without any complicated keyboard operation and improving the efficiency of the whole system. virtual reality is basically characterized by immersion,interaction and imagination. The designer and the user can get the comprehensive result of survey and design when the virtual reality technology is applied. The landscape architecture designing. Furthermore, this technology can show the user or designer the total information on landscape space, enable the user or designer do some long-distance on-line browsing and communicating,make computerassisted designing and decision, and help the public participate. However, there are several key problems in application of virtual reality technology landscape architecture designing, such as modeling of virtual environment, real-time 3D-imagegenerating technology, interactive technology and system integrating technology. With the rapid development of virtual reality technology and the active participation of the landscape architects, the application of the virtual reality technology. The landscape architectural designing will surely bring along the innovation of the methodology and essence of landscape architecture designing.
\end{abstract}

Keywords: Computer-assisted design, interaction technology, landscape architecture desiging, virtools virtual reality, virtual environment.

\section{INTRODUCTION}

Virtual reality (Virtual Reality, in short VR, Fig. (1)) technology, like network, is one of integrated information technology which has risen at the end of the 20th century. The VR technology has integrated the latest technology developments of computer Graphics, multimedia, artificial intelligence, multimedia, networks, parallel processing. Its real-time performance of 3D space capabilities, the operating environment involved in man and computer and bring the "personal experience" feeling, bring a change in the past interest less, rigid and passive conditions between man and computer, and make human exploration and study the micro-macro world greatly facilitated [1].

The application of Virtual reality technology for landscape architecture design provides strong support for us to observe the characteristics and behavior of the objective world. It can inspire designers who have interaction with the multidimensional information of environment and it can deepen their emotional and rational understanding, which can generate new creativity. The interaction with the multidimensional information of environment can enhance the scenic landscape creative means and in the quantitative and qualitative integrated master environment [2], emotional and rational understanding can be gained, consequently deepening the concept and expanding creative thinking ways. Although virtual reality technology is currently in the application in landscape garden design only for the exploration period, with the development of the technology, its impact on the landscape garden design will be even greater.

*Address correspondence to this author at the Hebei University of Engineering, Architecture College Handan, Hebei, 056038, China;

Tel: 13487564532; E-mail: Junhong@163.com
The use of virtual reality with police in several applications, such as planning, medical tests, and the layout of the workplace, but it is almost no industrial design of products, particularly products, I have the usability testing [3].

Virtual reality technologies such as the internet, is an integrated information technology, at the end of the 20th century. virtual reality integration of computer graphics, multimedia, artificial intelligence, multimedia, networks for the development of new technologies, the parallel behandeling. dimensional space, the environment and the participation of the people in the computer of "personal experience" feel, loss of interest in changes between man and computer rigid and passive situation, so the exploration and investigation of the microscopic world considerably easier.

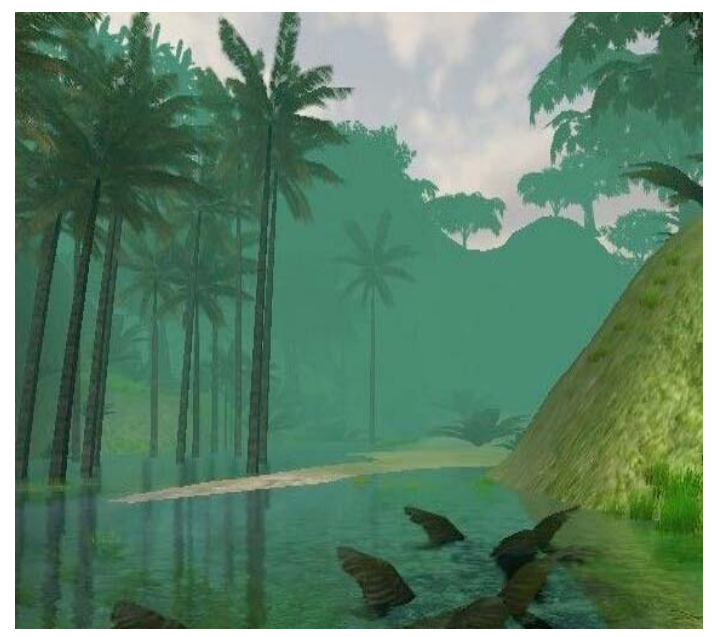

Fig. (1). Virtual reality technology.

2015 Bentham Open 


\section{DESIGN AND RESEARCH OF USER INTERFACE BASED ON VIRTUAL REALITY TECHNOLOGY}

User interface is a window of human-computer information transformation and exchanges, it is an important part of computer system and it is an indispensable part of information interchange between man and computer. (Fig. (2)) [4] With the rapid development of information technology, computer technology, new technology, new media applications, we have entered a new digital era. Information design, interactive design has penetrated into all aspects of social life, vision, hearing, and touch user experience such behavior will become an integral part of people's lives. Which, in the use of digital products, digital media and communication environment, the design of the user interface as improve product utility and attractiveness to strengthen the brand image and an important means to improve the quality of the user experience and also increasingly causing users and developers widespread concern. The study of the design of the user interface has become the most active research direction in recent years, design and computer fields.

The popular virtual reality technology is a comprehensive information technology bases on interactivity, immersion and imagination. Expressive of the real-time threedimensional space technology,' natural human-computer interaction in the operating environment and to bring immersive experience fundamentally changed between man and computer boring, stiff and passive interaction status quo. Virtual reality technology to provide a strong technical support for building the human-computer interaction viriualization environment and user interface model, creating a new field of research in human-computer interaction technology.

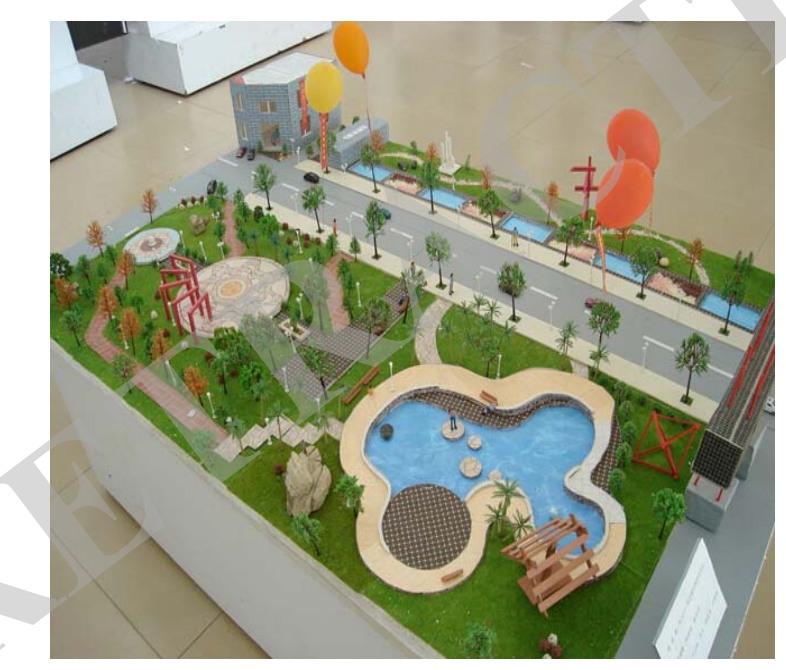

Fig. (2). Virtual reality scene.

The main object of this study is user interface design, the paper spreads background research of domestic and international user interface design, virtual reality technology and human-computer interaction. Analysis of the problem of the contradiction between the current user interface is design and model-making methods with interactive, experiential, immersive, the authenticity of human-computer interaction needs, based on virtual reality technology to innovative ideas in the design of the user interface. Through the user interface design process, design tools and production technology, the combination of different types of virtual reality technology, the characteristics of the system, and explore applications of virtual reality technology in the design of the user interface advantages and practical significance. (Fig. (3)) Existing equipment and technical support, the face of the virtual user interface model through tripartite design practice: first using ads Max software to create user role models and virtual reality model, user interface design process virtualization; second using Photo Shop, Illustrator and other software designed graphical user interface and overall grasp of the structure and style of interface interaction system; third, the use of virtual reality technology Virtools software to complete the design and Implementation of the interactive features of the user interface model, which topics perspective sexually valid authentication [5].

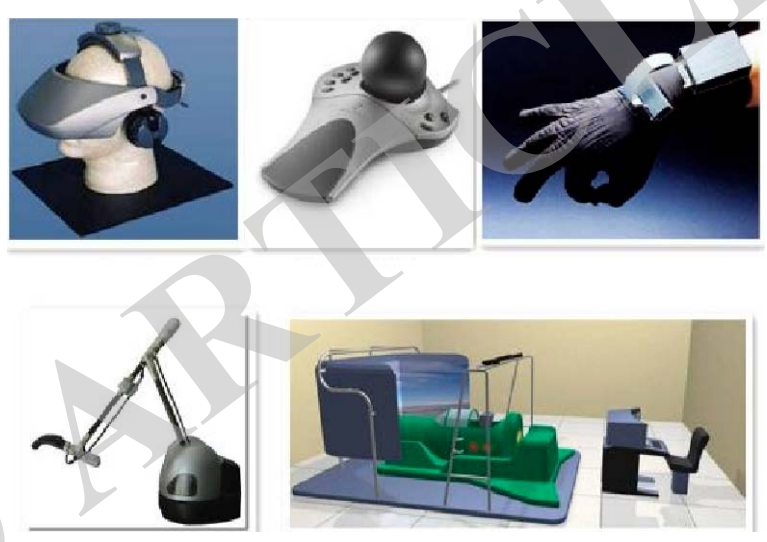

Fig. (3). Virtual reality equipment.

The topics proposed the introduction of virtual reality technology in a user interface model design and interactive production point of view, not only to meet the demand for human-computer interaction and user interface for interactive, experiential, immersive, authenticity, virtual reality technology trends and help to improve the efficiency of product development of the user interface, enhanced the realism of the virtual context, to extend the intuitive user interface design, interactivity and collaboration to bring new creative ideas for user interface design of the user interface design and development of human-computer interaction techniques with theoretical significance and application prospects.

\section{DESIGN AND IMPLEMENTATION OF VIRTUAL REALITY TECHNOLOGY}

\subsection{Tour Guide Training System}

The guide is to provide service for the tourists the first line of employees, not only is the tourist and addressed, or a region of the public relations representative, the tourism industry is the window of foreign relations, in tourism activities and tourism business has an important position and role. Scientific and effective to the tour guide personnel training, can improve guide quality, and improve the tourists' satisfaction, for tourism to create greater economic benefit and social benefit. The existing guide the training content, the technology is difficult to meet the social needs. Guide the lack of personnel professional ethics, the lack of interpersonal communication ability, emotional abuse of the phe- 
nomenon exists generally still, improve it guides the quality, scientific training system guide research is very necessary. At this time the virtual reality technology appear in our field of vision, the virtual reality technology as the 21 st century new a technology has been widely used in aviation, spaceflight, ship, railway, construction, civil, and scientific visualization, medical, education, entertainment, military, art, sports, etc. It has a multimedia information are intellectual, immersed sense, interaction, autonomy, etc. Using the virtual reality technology training system simulation and guide assessment system is a new attempt, a virtual environment is through the computer graphics consists of the three dimensional space, or make other reality of environment to a computer to generate lifelike "virtual environment", so that the user is on the vision to produce a immersion in a virtual environment feeling.

First elaborates the characteristics of virtual reality technology in China and in the present situation of the training, and from the training content, way to guide training are introduced, and also introduces the concept and characteristics of virtual reality, summarizes its application in education training and advantages; Second, the corresponding software and language use the introduction, this paper introduces Virtools development platform and its development process; According to the basic process of Virtools development, detailed introduces the realization of the system of the steps, attractions environmental simulation, interactive evaluation module and roaming animation touring, virtual spots of modeling methods and module and the implementation method, finally summarized the full text of the work, and points out the future research and development need further solve the problem.

In topographic map as modeling for reproduction, puts forward to establish virtual reality training system to guide this new way training mode to reform. The real with its force structure, with information query, roaming, cognitive, internal properties, teaching evaluation, etc widely intelligent virtual training system capacity, and to realize the tour guide daily training and examination of practice, the system can be applied to guide training institutions of education to students training, tour guide to guide the professionals and engaged in a professional. The application of this system will improve the efficiency of the training for the tour guide, regulating the content of the training to contribute.

\subsection{Design Software and Key Codes}

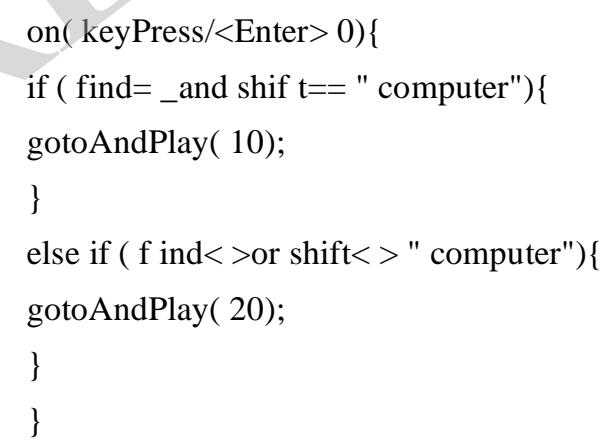

HRESULT CAsftMcRoadSeg; RenderRoadSurface LPDIRECT3DDEVICE9 pD3dDevice)
\}

pD3dDevice->SetFVF( VERTEX_TYPE夕I:;FVF);

pD3dDevice->SetMaterial( \&m_ RoadSurfaceMat); pD3dDevice->SetTexture ( 0, m_pRoadSurfaceTex ); pD3dDevice->SetStreamSource $\left(0, \mathrm{~m} \_\right.$pRoadSur-

faceVB ,

0, g_nVertexSize-I);

pD3dDevice->DrawPrimitive(D3DPT_TRIAN-

GLESTRIP, 0, m_nTriNum);

return S_OK; \}

1. Instead of the simulation of a prototype of a significant reduction of costs and "market". (Fig. (4) and (5))

2. Virtual reality can be considered a "channel for communication between the designers and users. as the vr, the commission communication is a continuous process from the perspective of the concept of,, exchange of information, should always explain and both sides of the designer, who is learning the translation, construction and the design of the state of the parts of the meaning of evolution.

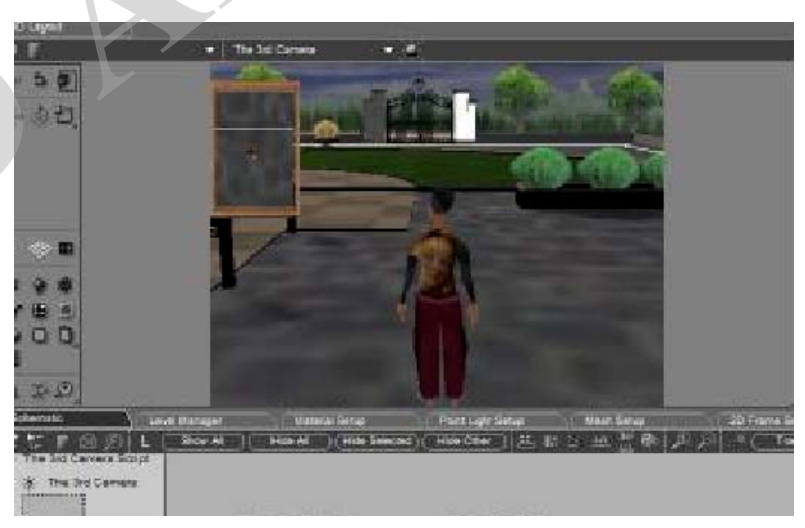

Fig. (4). Design software.

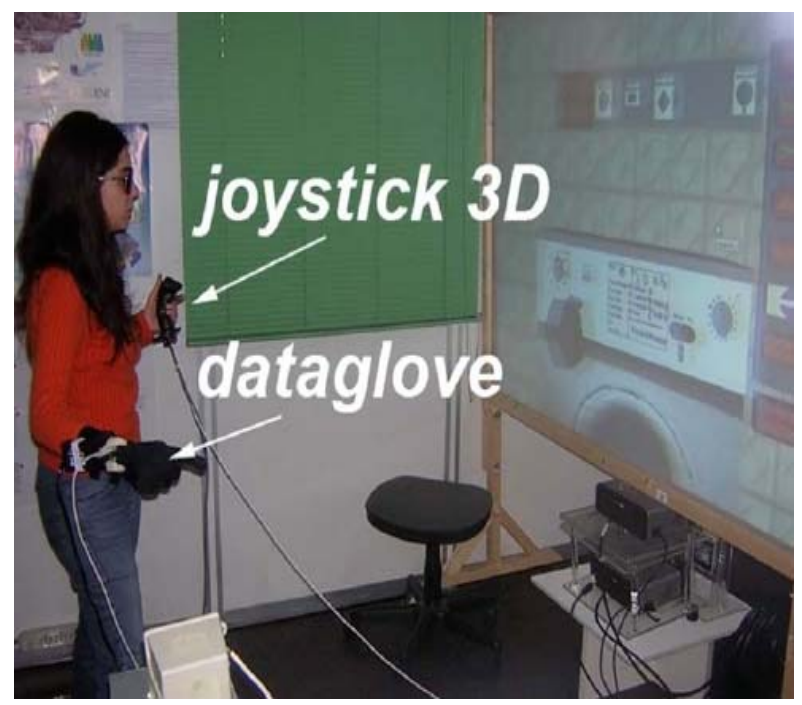

Fig. (5). Interaction devices. 


\section{HARDWARE DEVICES}

We test our method (Fig. 6) to passive stereo vision, including:

a $1.8 \times 1.2 \mathrm{~m} 2$;

$>$ two DLP NEC video-projectors with $1024 \times 768$ and 3000ANSI/lumen; (Fig. 5).

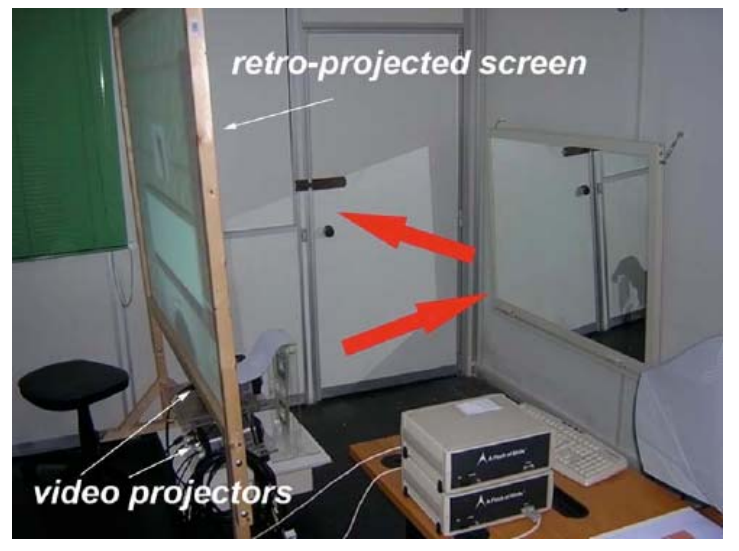

Fig. (6). Set-up used for the projection.

\subsection{Experimental Task and Participants}

The first study, the availability of tools to check the product, for me, a, C, e, pgfla and 3. From the scene to me. In the interface. In other words, it is this: when we define the usability testing of the virtual reality technology as an alternative to the traditional methods of evaluation, industrial products, such as virtual interface does not affect the evaluation of our own. The architecture is the virtual reality technology, equipment, products, availability in what degree of distortion degree.

In this experiment, the interaction between the results we compare the "users" product users, the availability of real "virtual" products evaluation, to the impact of the interaction between virtual interfaces. Referred to in this article is in the product, the evaluation, the current (market based on the microwave ovens and furnaces), because of the two different methods: first of all, usability testing, end users and the real product and other important interaction between users and furnace, in my model, such as the interaction between Fig. (7).

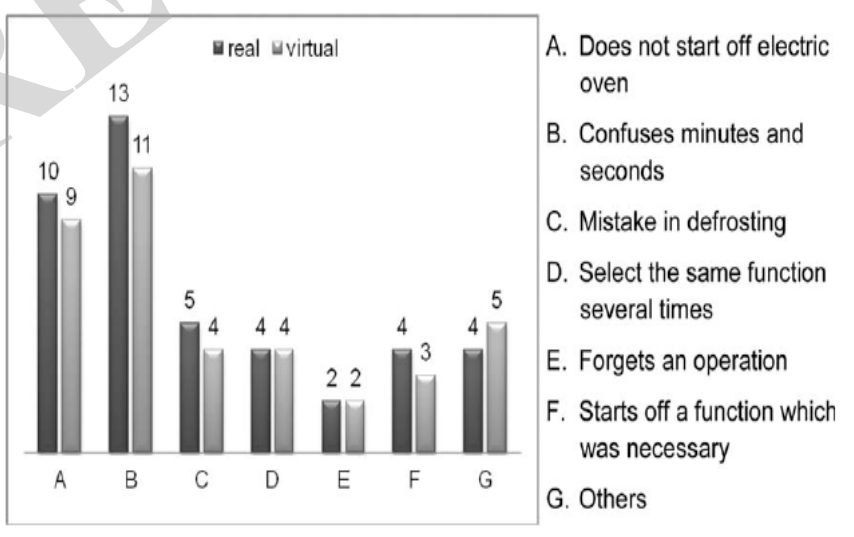

Fig. (7). Error typologies and their frequency during the test.
In order to carry out the test (which took place in the Department of Mechanical Engineering, University of Calabria) we chose 2 samples of 10 mechanical engineering students aged 23-26 (9 samples of users A (A mates and 11 females). $\mathrm{A}$ and $\mathrm{B}$ is a consistent feature, especially in the relevant product testing, our knowledge (only five students group in the microwave oven, you can request samples) and really interface usability testing samples of the evaluation, and puts forward the existing virtual interface (b).

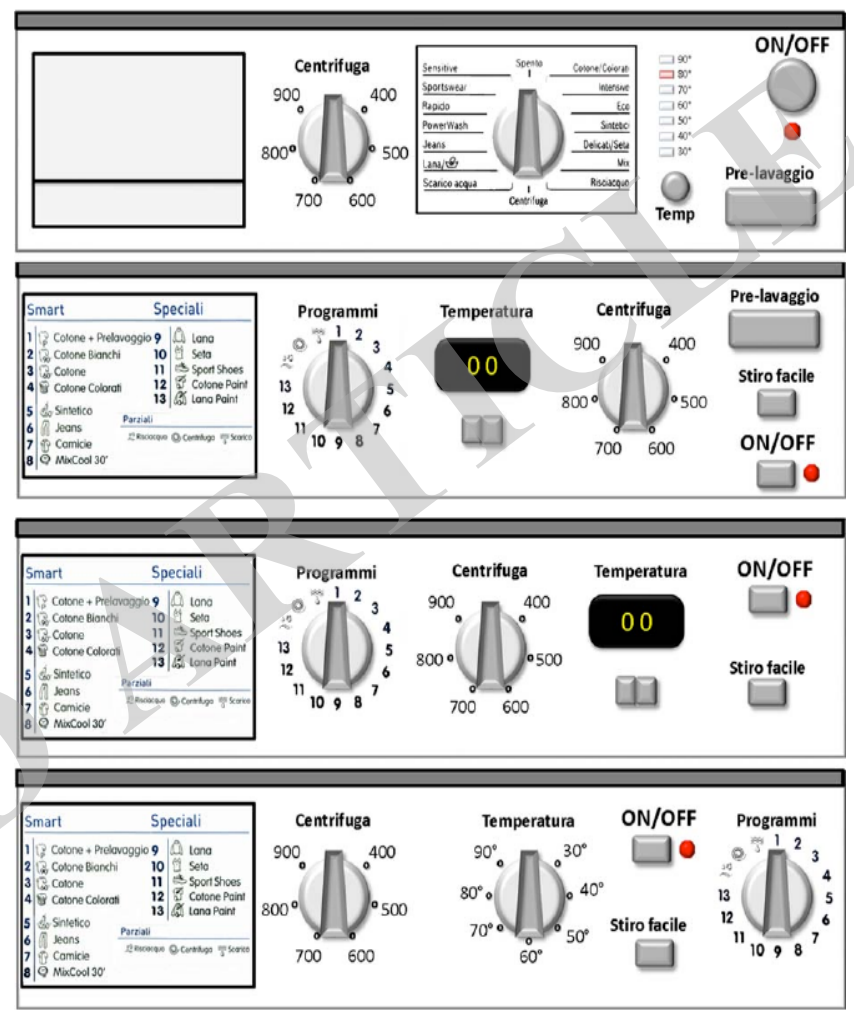

Fig. (8). Some of the 15 interface designed by the users.

The test results of two diametrically opposite results: on the one hand, the number of errors were found to be significantly (Table 1:6, very limited error of tasks and task 352 ) allows on the other hand, we have completed the task of statistical results (Table 1), but this just means that is an interface, completed the task time efficiency (ISO / DIS 9241 (11) and the efficiency of the program the number of errors), and believe, police have been actively interface usability. In fact, the trade relationship is conducive to development. But, first of all, I would like to point out that this approach can be greatly improved because of the map (8).

\subsection{Experimental Task and Participants}

Virtual reality system can be divided into different categories, which is dependent on certain factors, we want to emphasize particularly. Classification based on the possible level of abstraction, in a virtual environment (for example, abstract information, not the reality of the virtual environment (landscape) concrete and abstract elements), virtual reality (analog or digital acquisition), virtual environment and practical, it is difficult to tell the true colleague. Other possible factors (multi-channel perception of stimuli, are it?) Or provide quality of information. In this paper, an 
Table 1. One-Way A NOVA Table for number of error.

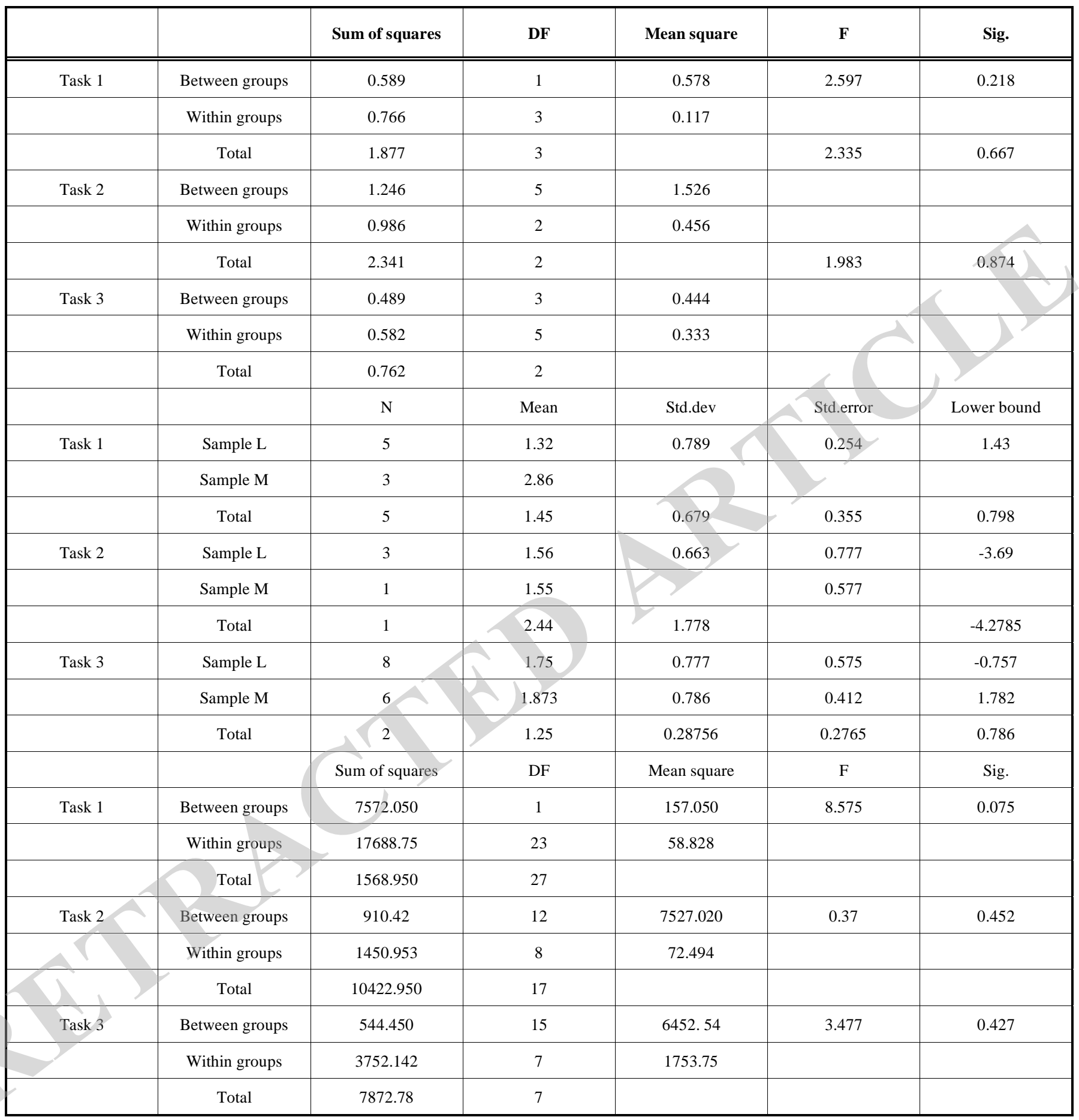

interactive level is provided by immersion in a virtual reality system based on classification, in particular taking into account the characteristics of the interface device.

In her car interactieve system of the achieve - $\mathrm{N}$ Worden, we onderverdeeld Grote class: "non interactieve", "meet gemedieerde interacties" and "gebruik minibus natuurlijke is completely." "Hebben Natuurlijke een van Deze, our system of voegen van het gebruik" Van de uitrusting at the foot of the van de interactive operation system (niveau om het ALS metafoor bemiddeling toetsenbord, joystick, etc.) apparatuur voor de Wang identificatie menselijk gedrag (zoals de opnames Van de apparatuur, spraakherkenning system, such as. Zodat er, or even directly gebruikers Van de Meer de relative activity.

As mentioned in the upper right corner of the virtual experience of the "good and meaningful classification system. Especially in the virtual cultural heritage, processing and application. In fact, the distinction between these applications is characterized by common actions that they are made by the public. This means that a typical user does not have 
the work experience of education, and no one in their first attempt is usually a complicated control device. Other popular virtual reality applications such as industry or medicine, users need to spend a lot of time preparing and simulating the system, the purpose is. Cultural heritage, in addition to their no professional users, does not mean that very limited time to constructive and pleasant experiences, so that they slowly learn. Ideally, users of the system can be clear, I do not want too many $5 \mathrm{~m}$ e, allus background and methods. This is justified if the interaction of the device is mediated by a more natural selection than. But it is usually not sufficient to fully interact with the method to effectively use these interfaces for the design. On the other hand, the system provides a better experience, but in general, lead to more powerful commitment and increased absorption of the concept and the countries of the user information, is usually very expensive, complex, installation, maintenance and management of special needs, many. So the best method is accurate target contour and target analysis, space resources.

\section{CONCLUSION}

The papers presented in the first chapter the main background of the subject's selection, the study scope, methods, and analyze relevant theories. Chapter II mostly deals with the changing process of landscape garden design ways from the visual thought to digital thought, from two-dimensional to multidimensional world, and reveals the need for virtual reality. Chapter III shows the creativity of virtual reality technology from the main concepts, features, development highlights, the current structure and application of virtual reality technology to mainstream technology. Chapter IV from theoretical level, explores virtual reality technology in the landscape garden design applications, and chapter $\mathrm{V}$ from the level of practice under existing conditions, describes how to construct and apply the VR in landscape architecture environment .The final paper analyzes obstacles which restrict virtual reality technology's development in the field of landscape garden design. In addition, some think of the meaning of the landscape garden design in the era of VR and prospect in the future in scenic landscape design was given by the author.

\section{CONFLICT OF INTEREST}

The authors confirm that this article content has no conflict of interest.

\section{ACKNOWLEDGEMENTS}

Declared none.

\section{REFERENCES}

[1] D. Pletincloc, D. Callebaut, A. E. Killebrew, and N. A. Silberman, "Yrtual-reality heritage presentation at Ename," Institute of Elecdical and Electronics Engineers Computer Society, Los Alamitos, CA, USA, 2010.

[2] S. N. Spencer, "Vrtual Reality and Visualisation. Association for Computing Machinery," Proceedings AFRIGRAPH 2011: 1st International Conference on Computer Graphics, 2011.

[3] Y. Liu, C. Xu, S. Li, and Y. Pan, "Three-dimensional dynamic GIS model for landscape planning," The International Society for Optical Engineering, pp.383-388, 2012.

[4] T. Honjo, and E. M. Lim, "Visualization of landscape by VRML system". Landscape and Urban Planning, vol. 55, no. 3, pp.175$183,2010$.

[5] T.K. Landauer, and J. Nielsen, "A mathematical model of the finding of usability problems," In: Proceedings of the ACM INTERCHI'93 Conference, Amsterdam, pp. 200-213.

Received: April 10, 2015
C Hongjun Chen; Licensee Bentham Open.

This is an open access article licensed under the terms of the (https://creativecommons.org/licenses/by/4.0/legalcode), which permits unrestricted, noncommercial use, distribution and reproduction in any medium, provided the work is properly cited. 